\title{
Aborichthys uniobarensis, a new species of river loach (Cypriniformes: Nemacheilidae) from Arunachal Pradesh, India
}

\author{
Prasanta Nanda $^{1}$, Krima Queen Machahary ${ }^{2}$, Lakpa Tamang ${ }^{2 *}$, Debangshu Narayan Das ${ }^{2}$ \\ ${ }^{I}$ Department of Zoology, Dera Natung Govt College, Itanagar, Arunachal Pradesh-791 113,India \\ ${ }^{2}$ Department of Zoology, Rajiv Gandhi University, Rono Hills, Doimukh, Arunachal Pradesh-791112, India
}

(Received: July 14, 2020; Revised: January 27 , 2021; Accepted: March 10, 2021; Published: March 17, 2021)

\begin{abstract}
A new species of nemacheilid loach, Aborichthys uniobarensis, is described from the Senkhi stream, upper Brahmaputra basin in Arunachal Pradesh, northeastern India. Aborichthys uniobarensis is distinguished from all congeners by the presence of 6-14 fused oblique bars along the dorso-lateral margin of the body, 21-28 oblique bars along the flank, vent closer to the snout tip than to the caudal fin base and caudal fin oval shaped with upper half more extended than lower.
\end{abstract}

Key words: Cypriniformes, Eastern Himalaya, Brahmaputra River, Northeastern, India.

\section{INTRODUCTION}

The nemacheilid genus Aborichthys Chaudhuri 1913 inhabit moderate to fast flowing rivers, streams and hill drainage comprises gravelly bed (Hora, 1925) and its distributional range is confined to Ganga-Brahmaputra drainage of northeastern India, Bhutan and Putao in Myanmar (Kosygin et al., 2019; Shangningam et al., 2019). They are characterized in having an elongate and slender body almost of parallel profiles from occiput to caudal-fin base, paired fins horizontally placed; dorsal fin situated slightly behind pelvic fins; vent situated close behind pelvic girdle; pelvic fins extending beyond the vent; more or less rounded to emarginated caudal fin, with brown to back concentric rings; two black ocellus- one at the upper extremity of basicaudal bar and another at the dorsal-fin origin; all fins considerably separated; flank consisting of oblique bars directed dorsad to ventrad (Hora, 1921, 1925; Chaudhuri, 1913; Kottelat, 1990) and usually presence of dorsal and ventral adipose crests (Shangningam et al., 2019).

In addition to two recently described species by Shangningam et al. (2019), the number of species raised to eleven viz. A. kempi Chaudhuri, 1913, A. elongatus Hora, 1921, A. garoensis Hora, 1921, A. tikaderi Barman, 1984, A. waikhomi Kosygin, 2012, Aborichthys cataracta Arunachalam et al., 2014 and A. verticauda Arunachalam et al., 2014, A. kailashi Shangningam et al. 2019, A. pangensis Shangningam et al. 2019, A. iphipaniensis Kosygin et al., 2019 and A. boutanensis (Griffith and McClelland 1842).

During a recent ichthyological survey in the Senkhi stream, specimens of Aborichthys were obtained. Further detailed study revealed that they represent an undescribed species, which is herein described as Aborichthys uniobarensis, new species.

\section{MATERIALS AND METHODS}

Sampling of fishes was done using cast net with $2 \mathrm{~m}$ diameter and $7 \mathrm{~mm}$ meshes. Collected fishes were freshly fixed in $10 \%$ formaldehyde in the beginning and then preserved in $70 \%$ ethanol. Counts and measurements were made point - to- point with a digital caliper on the left side of the specimens to the nearest $0.1 \mathrm{~mm}$. Counts and measurements follow Kottelat (1990) or self -explanatory. Dorsal and lateral head lengths and measurements of body parts are given as proportions of standard length (SL). Sub-units of the head are expressed as proportions of lateral head length (HL). Fin rays, cephalic lateralis sensory pores and scales were counted under a stereoscopic stereo-zoom microscope Magnus MS 24. Asterisk mark (*) after meristic value indicate holotype value.

The holotype is deposited in Estuarine Biology Regional Centre (EBRC), Zoological Survey of India (ZSI), Gopalpur, Orissa, India and paratypes in the Museum of Dera Natung Govt. College (DNGC), Itanagar, Arunachal Pradesh.

\section{TAXONOMY}

Aborichthys uniobarensis sp. nov.

(Figure 1a-e)

Holotype: EBRC/ZSI/F 12607, male, 83.9 mm SL; Senkhi stream, near Police Colony, Vivek Vihar, Itanagar $\left(27^{\circ} 4^{\prime} \mathrm{N}, 93^{\circ} 35^{\prime} \mathrm{E}\right), 218 \mathrm{~m}$ asl, upper Brahmaputra River basin, Papum pare District, Arunachal Pradesh; India, Tamang \& Nanda. 15 December, 2019.

Paratypes: DNGC F 05, 9 (5 males and 4 females), $51.0-82.5 \mathrm{~mm} \mathrm{SL}$, same data as holotype. 

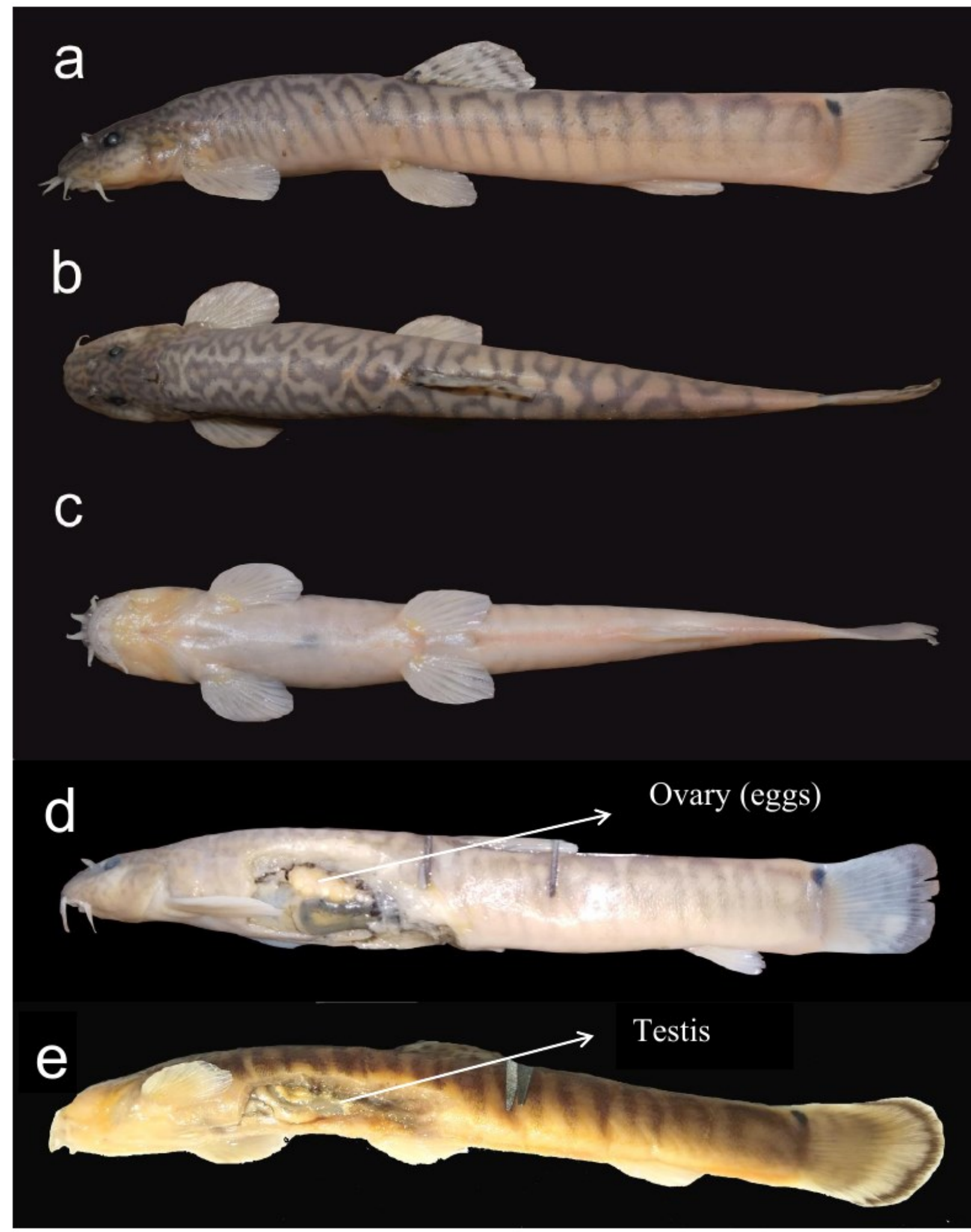

Figure 1. Aborichthys uniobarensis sp. nov., EBRC/ZSI/F 12607, holotype (male), $83.9 \mathrm{~mm}$; a, lateral, b, dorsal, and c, ventral views; d, DNGC 05, paratype (female), $75.0 \mathrm{~mm} \mathrm{SL}$; e, DNGC 05, paratype (male), $82.5 \mathrm{~mm} \mathrm{SL}$.

\section{Diagnosis}

Aborichthys uniobarensis is diagnosed from all congeners by the presence of 6-14 fused oblique bars along the dorso-lateral margin of the body (vs. rarely fused). Further, it chiefly differs from all congeners by the following combination of characters: 21-28 oblique bars on the body, dorsal and ventral adipose crests low, vent closer to the snout tip than to the caudal-fn base, caudal fin oval shaped with upper half more extended than lower, and comprised of two concentric black to light brown bars in male.

\section{Description}

For general appearance see Figure 1. Morphometric data are presented in Table 1. Body elongated and slender, body between pectoral fin and posterior tip of dorsal fin 
Table 1. Morphometric data of Aborichthys uniobarensis, sp. nov

\begin{tabular}{|c|c|c|c|}
\hline & Holotype & Range & $\operatorname{Mean} \pm \mathbf{S D}$ \\
\hline Standard length (mm) & 83.9 & $51-83.9$ & $69.7 \pm 10.4$ \\
\hline \multicolumn{4}{|l|}{ \% Standard Length } \\
\hline Lateral head length & 17.9 & $16.7-21.6$ & $18.4 \pm 1.5$ \\
\hline Dorsal head length & 14.3 & $13.1-17.1$ & $15.1 \pm 1.4$ \\
\hline Head width (max) & 12.2 & $12.1-14.4$ & $13.1 \pm 0.8$ \\
\hline Head depth at nape & 8.3 & $8.2-10.8$ & $9.4 \pm 0.9$ \\
\hline Body depth at dorsal-fin origin & 11.2 & $9.7-13.5$ & $11.7 \pm 1.0$ \\
\hline Body width at dorsal-fin origin & 9.8 & $9.7-11.8$ & $10.6 \pm 0.8$ \\
\hline Predorsal length & 45.3 & $45.3-52.0$ & $47.7 \pm 2.0$ \\
\hline Prepectoral length & 16.7 & $16.4-19.7$ & $17.5 \pm 1.2$ \\
\hline Prepelvic length & 41.7 & $41.7-49.2$ & $45.6 \pm 2.5$ \\
\hline Preanal length & 73.9 & $67.2-81.3$ & $75.7 \pm 4.2$ \\
\hline Pectoral-fin length & 13.0 & $13.0-18.4$ & $15.4 \pm 2.0$ \\
\hline Dorsal-fin length & 13.6 & $13.1-17.1$ & $14.9 \pm 1.3$ \\
\hline Dorsal-fin base length & 10.1 & $6.8-11.5$ & $9.3 \pm 1.4$ \\
\hline Pelvic-fin length & 12.6 & $12.4-15.9$ & $14.1 \pm 1.4$ \\
\hline Pelvic-fin base length & 3.0 & $2.7-39$ & $3.2 \pm 0.3$ \\
\hline Anal-fin length & 12.5 & $10.8-15.0$ & $13.3 \pm 1.4$ \\
\hline Anal-fin base length & 6.0 & $2.7-7.8$ & $5.6 \pm 1.3$ \\
\hline Caudal-fin length & 16.7 & $16.0-20.0$ & $17.9 \pm 1.4$ \\
\hline Caudal peduncle length & 20.0 & $15.4-20.5$ & $18.5 \pm 1.8$ \\
\hline Caudal peduncle depth & 10.1 & $8.6-11.8$ & $10.1 \pm 0.8$ \\
\hline Pectoral to pelvic-fin origin & 25.3 & $25.3-33.8$ & $28.8 \pm 2.4$ \\
\hline Pectoral to anal-fin origin & 57.8 & $56.8-79.9$ & $61.8 \pm 6.7$ \\
\hline Pelvic origin to anal-fin origin & 30.4 & $28.6-34.7$ & $30.7 \pm 1.6$ \\
\hline Pectoral-fin origin to vent & 36.5 & $36.5-44.5$ & $40.1 \pm 2.4$ \\
\hline Pelvic-fin origin to vent & 11.3 & $9.5-12.0$ & $11.0 \pm 0.8$ \\
\hline Vent to anal-fin origin & 20.5 & $17.1-22.8$ & $19.5 \pm 1.6$ \\
\hline Snout tip to vent & 52.4 & $52.4-59.9$ & $56.1 \pm 2.7$ \\
\hline Vent to caudal-fin base & 46.5 & $41.3-46.5$ & $43.7 \pm 1.8$ \\
\hline Anal-fin origin to caudal-fin base & 26.3 & $17.6-26.8$ & $24.6 \pm 2.6$ \\
\hline Tip of anal-fin to caudal-fin base & 13.2 & $6.7-14.4$ & $11.2 \pm 2.3$ \\
\hline \multicolumn{4}{|l|}{$\%$ Pelvic to anal-fin origin } \\
\hline Vent to anal-fin origin & 67.5 & $60.0-67.5$ & $63.3 \pm 2.8$ \\
\hline Vent to pelvic-fin origin & 37.3 & $30.9-38.9$ & $35.9 \pm 2.4$ \\
\hline \multicolumn{4}{|l|}{$\%$ Lateral head length } \\
\hline Head depth & 46.7 & $45.5-57.4$ & $51.4 \pm 4.4$ \\
\hline Upper jaw length & 26.7 & $24.6-32.8$ & $28.6 \pm 2.7$ \\
\hline Lower jaw length & 20.0 & $17.8-24.6$ & $21.7 \pm 2.3$ \\
\hline Snout length & 42.0 & $34.7-53.1$ & $42.5 \pm 5.7$ \\
\hline Prenasal length & 23.3 & $18.2-32.0$ & $26.2 \pm 3.8$ \\
\hline Eye diameter & 14.0 & $10.2-19.7$ & $14.3 \pm 3.0$ \\
\hline Inter-orbital width & 26.7 & $25.0-33.3$ & $29.3 \pm 2.9$ \\
\hline Inter-narial width & 16.7 & $16.2-22.7$ & $17.6 \pm 2.1$ \\
\hline Head width (max) & 68.0 & $63.6-75.4$ & $71.4 \pm 3.8$ \\
\hline Mouth width & 40.0 & $29.7-40.0$ & $36.3 \pm 3.2$ \\
\hline Head depth at nostril & 31.3 & $28.2-40.0$ & $33.4 \pm 3.6$ \\
\hline Head depth at pupil & 40.0 & $36.4-49.2$ & $43.4 \pm 3.8$ \\
\hline Medial rostral barbel length & 18.7 & $18.7-25.4$ & $22.5 \pm 2.6$ \\
\hline Lateral rostral barbel length & 20.0 & $16.8-24.6$ & $21.0 \pm 2.6$ \\
\hline Maxillary barbel length & 19.3 & $15.0-23.1$ & $18.5 \pm 2.7$ \\
\hline Caudal peduncle length/caudal peduncle depth & 2.0 & $1.4-2.3$ & $1.8 \pm 0.3$ \\
\hline \multicolumn{4}{|l|}{ \% Caudal peduncle length } \\
\hline Caudal peduncle depth & 50.6 & $44.4-70.0$ & $55.5 \pm 8.6$ \\
\hline
\end{tabular}



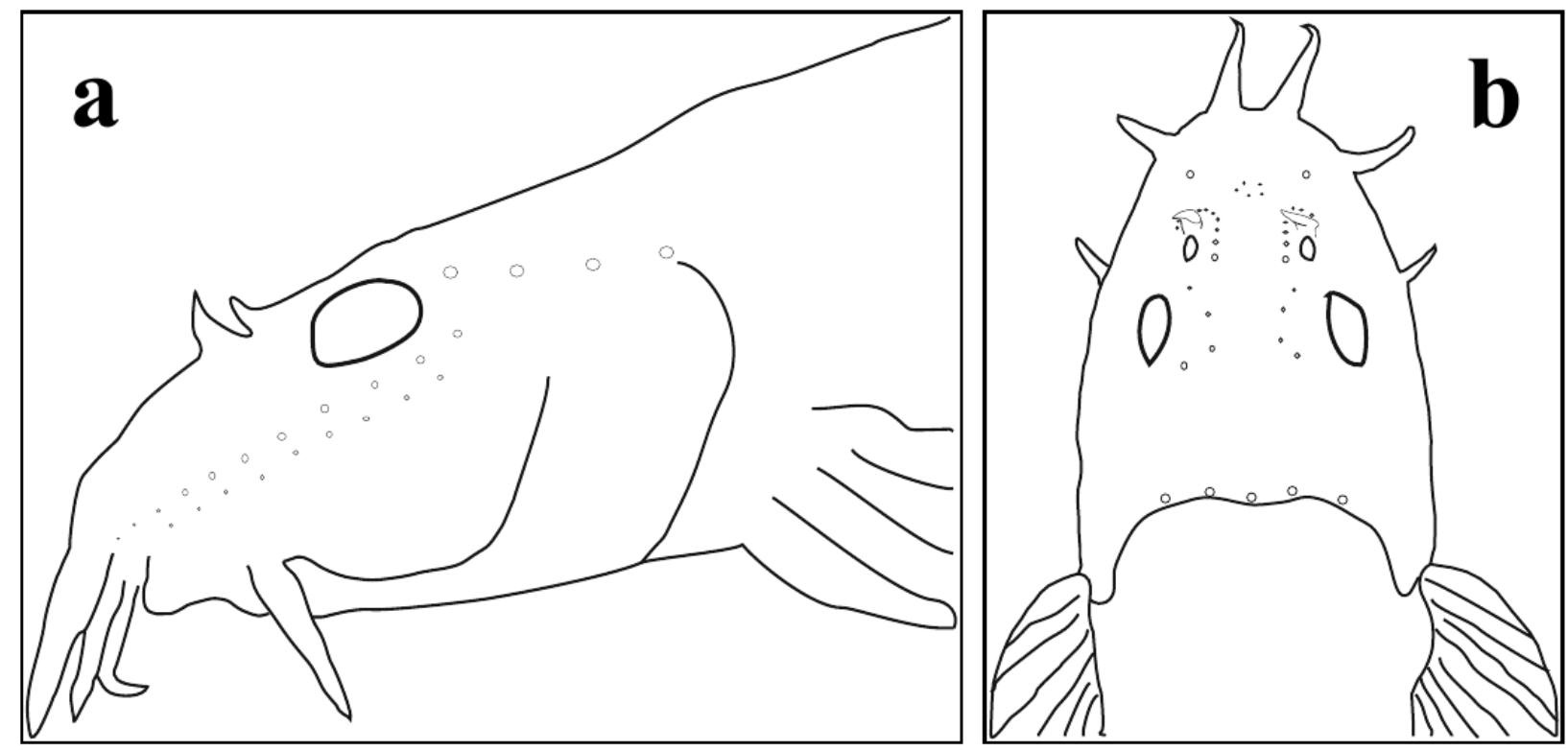

Figure 2. cephalic lateralis sensory pores: a-b, EBRC/ZSI/F 12607, holotype, male, $83.9 \mathrm{~mm}$ SL showing sensory pores.

cylindrical in cross section and thereafter compressed posteriorly. Dorsal profile evenly rising from snout tip to occiput, then horizontal up to point at vertical through tip of anal fin, thereafter, very gently raising upto caudal fin base and confluent with caudal fin. Ventral profile almost horizontal to anal-fin origin, then gently rising up to its posterior end, thereafter, again very gently raising and confluent with caudal fin, dorsal and ventral adipose crest significantly low (Figure 1d) and negligible in young specimens.

Head triangular when viewed dorsally and depressed, length 4.6-6.0 times its standard length, width greater than height, length slightly shorter than caudal fin in one paratype, almost equal in other 6 male and 3 female paratypes, but longer than all other fins, lateral head length longer than dorsal, dorsal profile evenly slope, and ventral flattened. Snout obtusely pointed in dorsal view. Eyes moderate to large 10.2-19.7 \% HL, dorsally situated, closer to tip of snout than to posterior extremity of opercle, not visible from ventral. Nostril closer to eye than to tip of snout, nares separated by triangular membrane flap dividing it into two parts; anterior nare tubular, attached with membrane flap, membrane flap raised up and slightly twisted, posterior nare roughly oval shaped, and anteriorly pointed.

Barbels three pairs: one pair maxillary and two pairs rostral, mostly longer than eye. Inner rostral barbel reaching posterior margin of knob of lower lip, but not reaching base of maxillary barbel, whereas outer rostral barbel reaching maxillary barbel base, maxillary barbel at vertical reaching to middle of eye or slightly exceed, but do not reaching to posterior margin.

Body embedded with minute cycloid scales, absent on ventral surface between isthmus and level of posterior end of pectoral-fin base, scales indistinct and deeply embedded on abdominal region. Lateral line complete with $34-65$ pores, of these $18-32$ pores closely set, externally visible, extending mostly before pelvic-fin origin, rest $16-33$ pores beyond distantly placed. Head sensory pores: double rows of infraorbital pores, first row with 10-11 and second row with 9-10 pores, temporal 4 (Figure 2a); supraorbital 4-5, occipital 5, series of 7-9 small pores surrounding nares, 4-5 small pores anterodorsal to nares, and 2 independent pores each in front of nares (Figure 2b). Other pores could not be examined because of indistinctiveness.

Dorsal fin with 2 simple and $7 \frac{1}{2}$ branched rays, last two rays originating from the same pterygiophore, inserted slightly posterior to pelvic-fin origin and at vertical almost mid of pectoral and anal-fin origins, nearer to snout tip (45.3-52.0\% SL) than to caudal-fin base (50.7$54.7 \%$ SL). Pectoral fin oval-shaped, horizontally placed, with 1 unbranched ray, 9(3), 10*(7) branched rays, tip extending to middle between pectoral- and pelvic-fin origin or sometime slightly exceeding. Pelvic fin oval shaped, horizontally placed, with 1 unbranched ray and $7 *(8)$ or 8 (2) branched rays, tip surpassing beyond vent, situated at vertical slightly anterior to dorsal -fin origin, origin closer to pectoral-fin origin than anal-fin origin in 6 specimens and in the middle in 4 specimens. Pelvic-fin base with a small fleshy axillary lobe. Anal fin elongate, with 2 unbranched and 51/2 branched rays, last two rays originating from the same pterygiophore, anterior margin slightly convex, posterior and distal margin straight, its tip separated by a distance of 6.7-14.4\% $\%$ SL from caudal-fin base, distance wider in male and closer in female. Caudal fin with 1 unbranched ray each on upper and lower end and $16^{*}(7), 17$ (1) or 15 (2) branched rays, all rays segmented, upper procurrent with $6(7), 5(2), 4 *(1)$ rays and lower with $3 *(5)$ and $4(5)$ rays, rays indistinct and fleshy. Caudal peduncle 1.4-2.3 times of its depth. Vent situated very closer to pelvic-fin origin than anal-fin origin, and closer to caudal-fin than to snout tip.

\section{Color in preservative}

In $70 \%$ ethanol, body background beige, flank with $21-$ 28 thin to moderate oblique brown bars, of which 6-14 paired bars fused along dorso-lateral margin of body; rarely 1-3 bars single, interspaces wider than bars, 3-4 anterior bars irregular. Dorsum of body between occiput and dorsal fin with a median brown stripe consisting creamy blotches or spots along the middle, blotches or spots feebly seen in younger specimens. Dorsum of head creamy consist of brown elongate, spots and irregular markings, usually three rows of brown stripes- one in front of nare and two in front of orbit. Cheek creamy with short brown irregular marks and spots; operculum 

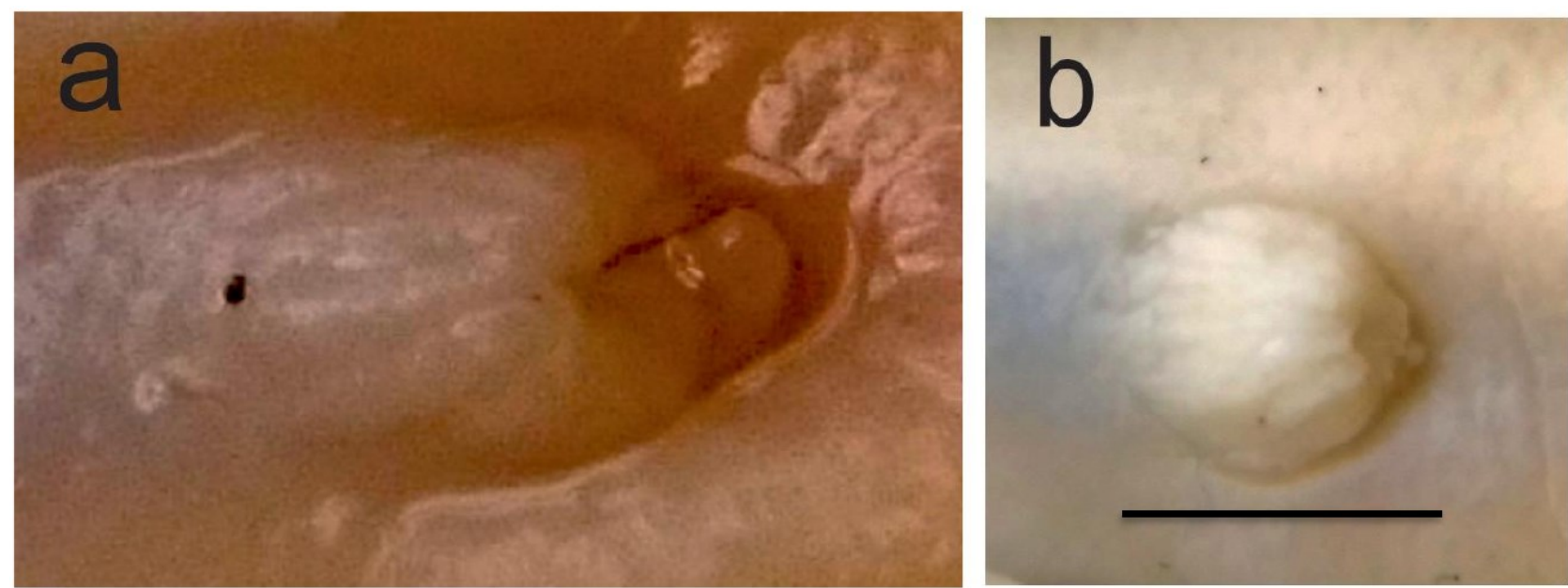

Figure 3. a, Aborichthys uniobarensis sp. nov., EBRC/ZSI/F 12607, holotype (male), 83.9 mm, showing elongate anus and large urogenital papilla; b, DNGC 05, paratype (female), $70.0 \mathrm{~mm}$ SL, showing rounded anus and small urogenital papilla (bar $=2 \mathrm{~mm})$.

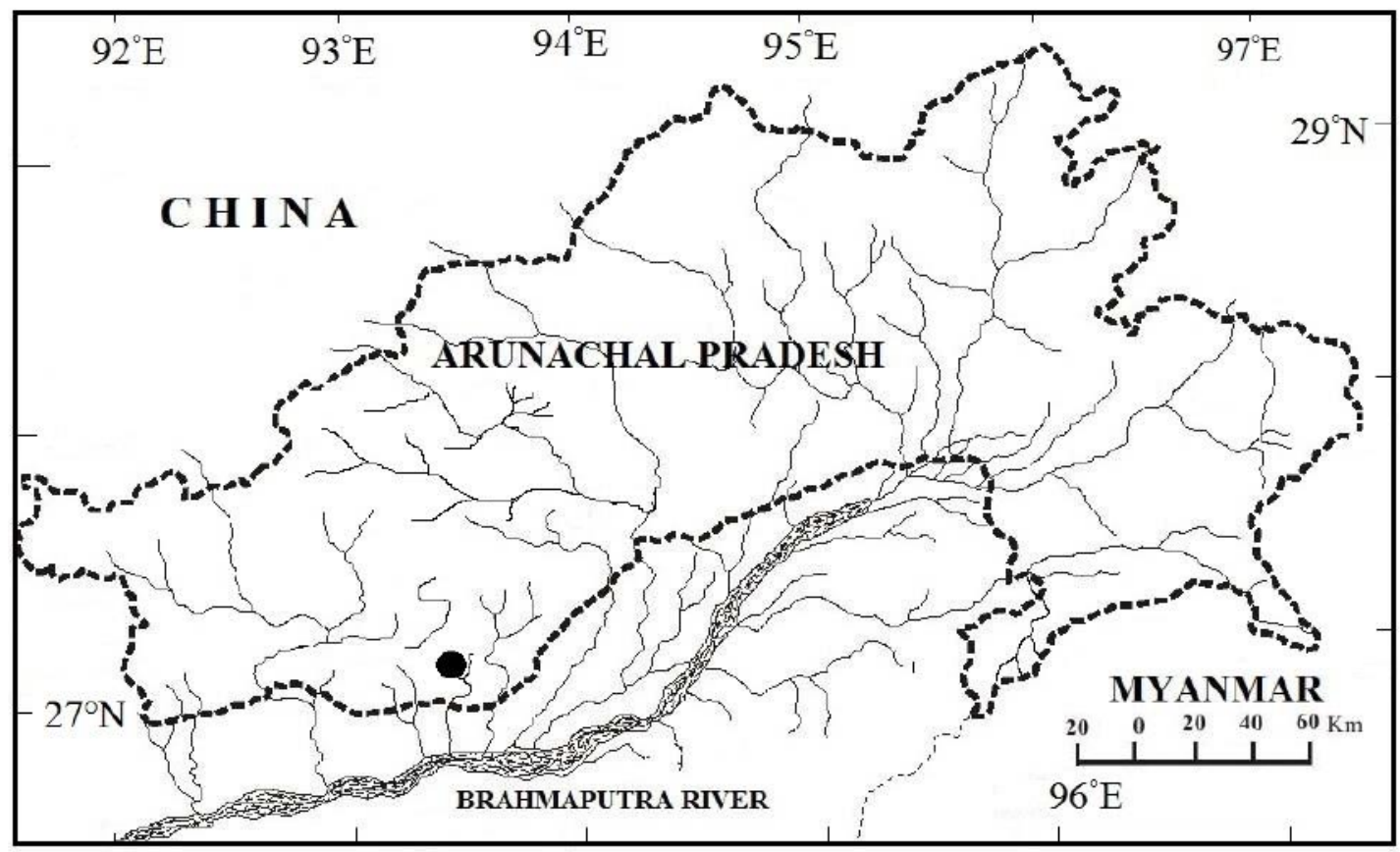

Figure 4. Map of Arunachal Pradesh showing type locality of Aborichthys uniobarensis, Senkhi stream at Police Colony, Itanagar.

region mostly with irregular brown marks.Ventral region of head yellowish to cream; chest to caudal base creamy, with a light orange longitudinal mid line between anus and anal-fin origin, but absent in three female specimens. Inter-radial membranes of dorsal, pectoral, pelvic and anal fins hyaline and radial with thin melanophores. Dorsal fin with 3-5 rows of brown spots and one dark brown ocellus at its base. Pectoral and pelvic fins dorsally plain. Caudal fin with two concentric bars in malesubdistal bar black, inner bar light brown appear as broad oval patch, whereas 3-4 light brown bars in female, rest hyaline to light brown (Figure 1a \& d). In live, caudal peduncle and fin pinkish.

Sexual dimorphism: Males exhibit longer body with dark pinkish caudal fin and peduncle region, whereas short body with light pinkish in females. In males, the caudal fin is slightly rounded with two black to light brown concentric rings, while truncate to obliquely truncated caudal fin with 3-4 narrow light brown bars
(Figure $1 \mathrm{~d} \& \mathrm{e}$ ). Anal fin tip is distantly separated from caudal base in males, whereas separated closely in females. Males have elongated anus and large conical urogenital papilla, whereas females have rounded and small conical urogenital papilla (Figure $3 a \& b$ ). Moreover, being a longer body in male, pelvic fin and pectoral-fin origins closer than anal-fin origin, whereas equidistant or slightly closer to anal-fin origin than pectoral-fin origin in female.

Distribution and habitat: Presently, Aborichthys uniobarensis is known from Senkhi stream, near Police colony, Vivek Vihar, Itanagar, Papum pare District, Arunachal Pradesh (Figure 4). We expect its distribution in other surrounding drainages about a radius of $30 \mathrm{~km}$. It flows southwest from Senkhi Valley up to Dera Natung Govt College and then turns eastward, which eventually falls in Pare River after covering about $30 \mathrm{~km}$ just before RCC bridge at Doimukh, which connect to Dikrong 
River. Further, Dikrong River eventually confluence with Brahmaputra River in Assam. River bed comprised of various sizes of stones-mostly medium sized boulders, and mixture of pebbles, cobbles, sands and large boulders. The water in the stream was cool, clear and moderate to fast flowing. Riparian vegetation in the type locality mostly replaced by human settlement in the left and right side comprises of grasses, shrubs and small trees, over steep hill slope. Other associated fish collected were, Cyprinidae: Opsarius bendelisis, Opsarius barna, Raiamas bola, Devario aequipinnatus, Tor putitora, Garra birostris, Garra annandalei, Neolissochilus hexagonolepis, Chagunius chagunio; Psilorhynchidae: Psilorhynchus balitora; Nemacheilidae: Schistura sp., Sisoridae: Pseudolaguvia sp, Glyptothorax sp.

Etymology: The species name is from the Latin unio means 'fuse or meet', and barensis refer to vertical oblique bars along the body, in allusion to most of the paired bars dorsally fused. A noun in apposition.

\section{DISCUSSION}

Until now, eleven species of Aborichthys are known to occur throughout eastern Himalaya region, viz., A. boutanensis, A. kempi, A. elongatus, A. garoensis, A. tikaderi, A. cataracta, A. verticauda, A. waikhomi, A. iphipaniensis, A. kailashi, and A. pangensis (Kosygin et al., 2019; Shangningam et al., 2019). Aborichthys uniobarensis is distinguished from all congeners in having the most of the paired oblique bars fused along the dorso-lateral margin of the body (vs. rarely fused in other congeners). Aborichthys uniobarensis is characterized in having position of the vent closer to the snout tip than to the caudal-fin base as similar to A. garoensis, $A$. tikaderi and A. iphipaniensis. As per the sketch diagram of Aborichthys garoensis (text Figure 1) illustrated by Hora (1921) the patterns of vertical bars on body and an elongate anus shares with $A$. uniobarensis. However, the number of bars beyond dorsal fin tip is about 14 , whereas mostly 9-10 (8) and rarely 12 (2) in case of $A$. uniobarensis. This might have resulted that the number of bars in A. garoensis is higher 32-33 than $A$. uniobarensis 21-28. Further, the type locality of A. garoensis is far away (Garo Hills, Assam= Meghalaya) towards south covering a geographical distance of about $512 \mathrm{~km}$ which was collected at an altitude of 12001500 feet, whereas A. uniobarensis were obtained from an altitude of 720 feet. Further, Aborichthys uniobarensis is distinguished from $A$. garoensis in having longer prepectoral (16.4-19.7\% SL vs. 14.6-16.3); more forward position of vent (distance between vent and caudal-fin base $41.3-46.5 \%$ SL vs. 47.5-49.2); greater interorbital space (25.0-33.3\% HL vs. 23.3-23.6) and narrower mouth (29.7-40.0\% HL vs. 42-46.6); from A. tikaderi in having higher number (21-28 vs. 16-20) vertical bars on the body, oval shaped caudal fin with upper half more extending than lower (vs. almost circularly rounded in A. tikaderi; Figure 1a with Kosygin, 2012: Figure 5e), a greater prepectoral (16.4$19.7 \%$ SL vs. 14.9-16.2), pectoral to pelvic fin origin (25.3-33.8 vs. 22.6-24.7), pectoral-fin origin to vent (36.5-44.5 vs. 30.4-33.1), pelvic fin to vent (9.5- 12.0 vs. $6.6-7.4)$, snout tip to vent (52.4- 59.9 vs. $45.8-51.6)$, pectoral to anal fin origin (56.8-79.9 vs. 47.1-50.6) and pelvic to anal-fin origin (28.6-34.7 vs. 22.3-28.4), a shorter caudal fin (16.0-20.0 vs. 20.2-21.2) and lesser caudal peduncle depth (8.6-11.8\% SL vs. 12.7-13.7); from $A$. iphipaniensis in having more vertical bars along the body (21-28 vs. 33-35), a greater predorsal (45.3$52.0 \%$ SL. vs. 42.4-44.4), shorter caudal peduncle (15.4 $-20.5 \%$ SL vs. 21.5-23.3), shorter vent to caudal base distance (41.3-46.3\% SL vs. 52.0-56.2), and longer distance between snout tip and vent $(52.4-59.9 \%$ SL vs. 44.2-48.3).

Further, it differs from other congeners except A. boutanensis and $A$. kempi in having a fewer oblique bars along the body (21-28 vs. 31-33 in A. elongatus; 32 -35 in A. cataracta; $30-35$ in A. verticauda; $28-36$ in A. kailashi; and 34-38 in A. pangensis), and more (21-28 vs. $12-16$ in $A$. waikhomi). Among congeners, Aborichthys uniobarensis shares with A. kempi, A. iphipaniensis and A. kailashi in having oval-shaped caudal fin, of which upper half is considerably more extending than lower half, causing an oblique distal margin with two concentric rings. However, Aborichthys uniobarensis is further: distinguished from $A$. kempi in having lower and shorter (vs. higher and longer) dorsal adipose crests in male, from A. kailashi in having the mouth moderately (vs. widely) arched, oblique bars on body widely (vs. narrowly) interspaced; dorsal and ventral adipose crests on caudal peduncle lower, short and thick (vs. higher, longer and thin), a deeper body (9.7-13.5\% SL vs. 7.5-9.2), a longer caudal- (16.0-20.0\% SL vs. 14.0 $15.2)$, pectoral- (13.0-18.4 \% SL vs. 10.7-13.4) and pelvic fins (12.4-15.9\% SL vs. 10.9-12.4), and a larger eye (10.2-19.7 \% SL vs. 8-10). Aborichthys uniobarensis differs from $A$. boutanensis in having lower (vs. higher) dorsal and ventral adipose crests on caudal peduncle (compare Figure1a with Thoni \& Hart, 2015; Figure $1 \mathrm{a}$, holotype BMNH1860.3.14.775, $104.7 \mathrm{~mm}$ SL), and fewer branched pectoral-fin rays (9-10 vs. 12).

Aborichthys uniobarensis can be further distinguished from A. elongatus, A. waikhomi, A. verticauda, and $A$. pangensis in having caudal fin oval shaped, with slight dorso-ventrally directed oblique distal margin (vs. circularly rounded in $A$. elongatus; truncated in A. waikhomi; A. verticauda and A. pangensis (Figure 1a with Kosygin, 2012: Figure 5 a,b,f; Arunachalam et al., 2014: Figure 4a; Shangningam et al., 2019: Figure 3 for A. pangensis). It further differs from A. elongatus in having wider interorbital space (25.0-33.3\% HL vs. $22.2-$ 22.30 ), longer distance between vent and anal-fin origin (17.1-22.8\% SL vs. 13.5-14.3), longer distance between vent and caudal-fin base (41.3-46.5\% SL vs. $38.3-39.1)$; from A. waikhomi in having shallow body $(9.7-13.5 \%$ SL vs. 12.8-15.8); from $A$. verticauda in having a greater prepectoral (16.4-19.7\% SL vs. 20.0-24.2), distance between tip of pectoral- and pelvic fin origins equal (vs. less than) length of pectoral fin; and from A. cataracta in having greater distance between pectoral- and anal-fin origins (56.8-79.9\% SL vs. $50.3-56.8$ ), fewer (10 vs. 15 ) oblique bars beyond end of dorsal fin even in large specimen $83.7 \mathrm{~mm}$ SL (compare Figure 1a with Arunachalam et al., 2014; Figure 1a).

Distinguishing sexual dimorphic characters of Aborichthys uniobarensis mentioned above is further supported by Aborichthys kempi (topotype), RGUMF 0517, male, $110.0 \mathrm{~mm}$ SL and RGUMF 0517, female, $74.5 \mathrm{~mm} \mathrm{SL}$. Hence, we assume that the individual having elongate body and oval shaped caudal fin with two black to light brown concentric rings are males, whereas short body and truncate to slightly rounded with 3-4 cross bars are females. 


\section{Comparative material}

Aborichthys kempi, topotype, 6 specimens, 67.1-110 mm SL, RGUMF 0517, 05.ii.2020, Egar stream between Rottung and Renging village, Arunachal Pradesh, India, Coll. O. Ering.

A. waikhomi, paratypes, 3 specimens, 61.0-66.5 $\mathrm{mm}$ SL, V/APRC/ZSI/P-519, 05.xi.2009, a stream of Noa-Dihing river near Hornbill camp, Namdapha, Arunachal Pradesh, India, Coll. J.K. De \& party.Additional data from Kosygin, 2012.

A. iphipaniensis, paratypes, 3 specimens, 107.5 -120.8 mm SL, ZSI/V/APRC/P-1659, 4.iv.2016, Iphipani River at Roing, Lower Dibang Valley, Brahmaputra River basin, Arunachal Pradesh, India, coll. S. Devi and party. Additional data from Kosygin et al., 2019.

A. kailashi, paratypes, 2 specimens, $89-113 \mathrm{~mm}$ SL, ZSI/V/ APRC/P 786, 09.xi. 2013, Pange River at Arolenching, Ziro, Lower Subansiri district, Arunachal Pradesh, India, Coll. B. Sinha \& party. Additional data from Shangningam et al., 2019.

A. cataracta, paratype, 1 specimen, $92.6 \mathrm{~mm}$ SL, ZSI/SRS F 8575, 18.vi.2011, stream joining with Ranga River, Hong Village, Lower Subansiri district, Arunachal Pradesh, India, Coll. M. Arunachalam \& party. Additional data from Arunachalam et al., 2014.

A. verticauda, paratype, 1 specimen, $65.6 \mathrm{~mm}$ SL, ZSI/SRS F 8579, 17.vi.2011, a tributary of Ranga River) $7 \mathrm{~km}$ away from Hola camp, Lower Subansiri district, Arunachal Pradesh, India, Coll. M. Arunachalam \& party. Additional data from Arunachalam et al., 2014.

Data for A. boutanensis from Thoni \& Hart, 2015; for A. elongatus, A. tikaderi, A. garoensis from Arunachalam et al., 2014 and Shangningam et al., 2019 and Kosygin et al., 2019; for A. pangenesis from Shangningam et al., 2019; for $A$. cataracta and $A$. verticauda from Arunachalam et al., 2014.

\section{ACKNOWLEDGEMENT}

We are grateful to Dr. N.T. Rikam, Principal, DNGC, Itanagar for providing laboratory facilities. Thanks to Department of Zoology, RGU, for providing access to topotype of Aborichthys kempi.

\section{REFERENCES}

Arunachalam, M., Raja, M., Malaiammal, P. and R.L. Mayden 2014. New species of Aborichthys (Cypriniformes: Balitoridae) from Arunachal Pradesh, India. Species 7: 33-47.

Barman, R.P. 1984 . A new cobitid fish of the genus Aborichthys Chaudhuri (Pisces: Cobitidae) from India. Journal of Bombay natural History Society 81 (3): 680-683.

Chaudhuri, B.L. 1913. Zoological result of the Abor expedition.1911-1912. XVIII.Fish.Records of the Indian Museum 8: 243-258.

Hora, S.L. 1921. On some new or rare species of fish from the Eastern Himalayas. Records of the Indian Museum 22(5): 731-744, pl. 1.

Hora, S.L. 1925. Notes on fishes in the Indian museum. VIII. On the loaches of the genus Aborichthys Chaudhuri. Records of the Indian Museum 27 (3): 23-236.

Kosygin, L. 2012. Aborichthyswaikhomi, a new species of fish (Teleostei: Nemacheilidae) from Arunachal Pradesh. Records of the Zoological Survey of India 112(1): 49-55.

Kosygin, L., Gurumayum, S.D., Singh, P. and B.R. Chowdhury 2019. Aborichthys iphipaniensis, a new species of loach (Cypriniformes: Nemacheilidae) from Arunachal Pradesh, India. Uttar Pradesh Journal of Zoology 39(2): 69-75.

Kottelat, M. 1990. Indochinese nemacheilines, a revision of nemacheiline loaches (Pisces: Cypriniformes) of Thailand, Burma, Laos, Cambodia and southern Vietnam.Verlag, Dr. Friedrich Pfiel, Munchen, $261 \mathrm{pp}$.

Shangningam, B., Kosygin, L., Sinha, B. and S.D. Gurumayum2019.Aborichthyskailashi and $A$. pangensis (Cypriniformes: Nemacheilidae), two new species from Arunachal Pradesh, India. Ichthyological Exploration of Freshwaters 1-10. https://doi.org/10.23788/IEF-1123

Thoni, R.J., Hart R. 2015. Repatriating a lost name: notes on McClelland and Griffith's Cobitisboutanensis (Cypriniformes: Nemacheilidae). Zootaxa 3999 (2): 291-294. 